\section{Lateral Gaze Palsy}

Douglas I. Katz

Department of Neurology, Boston University

School of Medicine, Braintree, MA, USA

\section{Synonyms}

Horizontal gaze palsy

\section{Definition}

Lateral gaze palsy is an inability to produce horizontal, conjugate eye movements in one or both directions. Lesions of the cranial nerve VI (abducens) nucleus in the pons cause ipsilateral, horizontal gaze palsy by disrupting motoneurons that innervate the ipsilateral lateral rectus muscle by way of cranial nerve VI and interneurons that connect to the contralateral cranial nerve III nucleus in the midbrain, via the medial longitudinal fasciculus, to stimulate the medial rectus of the opposite eye. Lesions of the paramedian pontine reticular formation, adjacent to the abducens nucleus, may cause lateral gaze palsy, particularly involving ipsilateral saccadic eye movements. Lesions of the frontal or parietal cortical eye fields may also cause weakness of horizontal gaze (contralateral to frontal lesions and ipsilateral to parietal lesions) that becomes more subtle over time.

\section{Cross-References}

- Internuclear Ophthalmoplegia

- Oculomotor Nerve

$\checkmark$ Pons

\section{References and Readings}

Leigh, R. J., \& Zee, D. S. (2006). The neurology of eye movements (4th ed.). New York: Oxford University Press. 